\title{
TEMA-TEMA MIMPI PSIKO-SPIRITUAL KYAI
}

\author{
H. Fuad Nashori
}

Universitas islan indonesia

\section{INTISARI}

\begin{abstract}
Penelitian in bertujuan untuk mendeskripsikan tema-tema mimpi psikospiritual kyai. Secara umum, tema-tema mimpi psiko-spiritual dibedakan menjadi empat, yaitu prediksi, retrospeksi, petunjuk, dan peringatan. Fespondennya adalah lima kyaj pengasuh pondok pesantren yang ting gal of Yogyakarta. Untuk mengetahui tema-tema mimpi kyai dilakukan wawancara Setelahdilakukan wawancara dengan sejumlah kyai pengasuh Pondok Pesantren of Yogyakarta diketahui bahwa mimpi-minpi yang dialami kyai banyak yang berdimensi psiko-spirifual. Tema-lema mimpi kyai meliputi mimpl psiko-spiritual yang berisi refrospeksi (bertemu Nabi Muhammad, bertemu Nabi Khidzir), prediksi (sumur yang tak habis airnya walau ditimba terus menerus, kursi yang diperoleh partai, Merapi akan meletus), petunjuk (pendirian pos kosehatan pondok pesantren, obaf untuk menyembuhkan penyakit, menilu lbrahim yang tabah menjalani kesulitan hidup), peringatan (jauhi seseorang yang dilinginkan sebagaj calon jodoh, hindari warne mer ah).
\end{abstract}

Kata Kunci: Tema Mimpi, Kyai, Mimpi Prediktif, Mimpi Retrospektif

H. Fuad Nashori, S.Psi, M.Si, adalah dosen Fakultas Psikologi dan Peneliti Lembaga Penelitian Universitas Islam Indonesia. Meminati kajian dan melakukan berbagai penelitian dengan topik penalaran moral, kreativitas, kemandirian, religiusilas, mimpl, keluarga.

\section{LATAR BELAKANG}

TK thering dihibur oleh orang-orang di sekitar kita bahwa mimpi adalah bungatidur. Mereka mengatakan bahwa mimpi tidak memiliki makna apa-apa selain bahwa la secara nyata hadir dalam tidur kita. Dikatakan oleh mereka bahwa mimpi buruk yang kita alami semata-mata karena pengaruh fisik kita. Mungkin karena tangan kita sedang tertindih tubuh, dan mungkin pula karena sebelum dan selama tidur kta diselimuti kelelahan yang amat kuat.

Kalau sudah belajar teori psikoanalisis kita mengetahul pendapat yang mengungkapkan bahwa mimpi yang kita alami 
adalah ekspresi dari pengalaman dan keinginan kita yang terpendam. Karena di alam nyata sulit bagi kita untuk mengungkapkan kekesalan, keresahan, kemarahan, dendam, dan yang sejenisnya kepada objek-objek yang menjadi sumber rasa marah, maka muncullah keinginan itu dalam bentuk mimpi. Sebuah teori terkenal dari Sigmund Freud adalah "setiap anak bermimpi menyakiti atau membunuh bapaknya" (Berry dkk-1 1999). Mimpi tersebut muncul dikarenakan anak sangat cemburu(jealousy) terhadap ayahnya yang menyayangi dan disayangi ibunya (mother's lover). Kecemburuan yang bertumpuk-tumpuk ini akhirnya menjadikan adanya kebencian sang anak kepada ayahnya. Kebencian tersebut akhirnya terekspresi dalam bentuk mimpi "sang anak menyakiti atau membunuh ayahnya."

Pendapat yang menyatakan bahwa seseorang bermimpi semata-mata faktor fisik dan psikologis memperoleh sanggahan dari banyak kalangan, terutama ahli-ahli dan tokoh-tokoh agama serta ahli parapsikologi. Ahli-ahli dan tokoh-tokoh agama berpendapat bahwa dalam berbagai teks kitab suci ditunjukkan adanya tokoh-tokoh sejarah, terutama Nabi-nabi, yang bermimpi dan isi mimpinya jelas-jelas merupakan isyarat masa depan sekaligus pengetahuan kehidupan masa lalu. Salah satu contohnya adalah mimpi Nabi Muhammad bahwa umat Islam akan memasuki kota Makkah yang saat itu dihuni orang-orang yang tidak beriman tanpa adanya perlawanan dan gangguan (QS alFath, 48:27); dan temyata mimpi ini mewujud dalam kehidupan nyata umat Islam.

Tokoh-tokoh den ahli agama juga mengungkapkan bahwa dalam kehidupan masyarakat sudah biasa dilakukan apa yang disebut shalat istikharah, yaitu suatu shalat yang dimaksudkan untuk memperoleh petunjuk dari Tuhan tentang pilihan-pilihan hidup. Salah satu hal yang dharapkan orang- orang dari shalah istikharah adalah mimpi yang berisi petunjuk tentang siapa jodoh mereka.

Tidak kurang dari itu, ahli-ahli parapsikologi juga mengungkapkan berbagai fakta yang menunjukkan bahwa pada sebagian manusia kemampuan prekognisi (precognition) merupakan kemampuan yang banyak ditopang oleh mimpi. Pengetahuan seseorang tentang apa yang bakal terjadi dan bahkan juga antisipasi terbaik apa yang harus dilakukan biasa diperoleh melalui mimpi, di samping diperoleh melalui pernecahan masalah atau melalui itham.

Yang menarik adalah banyaknya fenomena ahli-ahli agama atau or ang-orang yang terkemuka dalam beragama yang memiliki mimpi yang mengandung isyaratisyarat spiritual, termasuk pengetahuan, petunjuk hidup, dan peringatan hidup di masa depan (mimpi prediktif) serta kehidupan masa lalu (mimpi retrospektif). Sebagai misal, setiap kali bensaha memperoleh jawaban atas pertanyaan intelektualnya Ibnu Sina selalu menyelingi kegiatannya dengan melakukan shalat sunnat. Ternyata, banyak bermunculan ide, pengetahuan, dan petunjuk dalam mimpi selama tidurnya (Nashori, 1999).

Bukan hanya abli agama, para pelajar atau santri uga banyak yang memiliki mimpi yang mengandung isyarat masa depan. Salah salu contoh orang yang pada santrinya banyak memperoleh mimpi adalah Hidayat Nur Wakhid (Jawa Pos, 2000), seorang dosen IAlN Jakarta yang jugaPresiden Partai Keadilan. Diceritakannya bahwa sewaktu belajar ilmu agama dan menempa dirl di Pesantren Moderen GONTOR, Wakhid banyak menemukan mimpi yang isinya adalah soal-soal yang bakal diberikan pada waktu ujian esok harinya. Dalam kenyataannya, apa yang ditemukan dalam mimpi ternyata juga benar-benar ditemukan dalam ujian yang nyata. 
Salah satu sosok atau figur tokoh agama yang cukup menonjol dalam lingkungan masyarakat Jawa khususnya di Yogyakarta, adalah kyai. Kyai konteks penelitian ini adalah panggilan yang diberikan kepada seseorang yang memikikengetahuan agama serta perilaku agama yang kuat. Umumnya mereka memimpin atau mengasuh pondok pesantren. Sebagai orang yang dekat dengan Tuhan, banyak pengalaman keagamaan yang mereka miliki. Salah satu yang cukup menonjol adalah pengalaman yang berkaltan dengan mimpi. Sejauh ini penelititelah banyak mendengarkan kisah mereka tentang mimpimirnipi yang mereka alami. Dalam kutur santí Jawa, kyai merupakan salah satu sumber rujukan dalam menjalani kehidupan. Adanya gambaran tentang berbagai macam sisi kehidupan kyai, khususnya yang berkaitan dengan pengelaman keagamaan seperti mimpi ini, akan menghasilkan potret yang lebh lengkap tentang kehidupan mereka.

Pertanyaanyang dapat kitaajukan adalah benarkah mimpi memiliki isyarat-isyarat spiritual? Adakah mimpi yang berdimensi predjktif, petunjuk, peringatan, dan retrospektif? Adakah mimpi yang memiliki aspek sosial dan bukan semata-mata personal?

Penelitian ini akan mengungkapkan perspektif teoritis dan juga perspektif empiris atas mimpi-mimpi yang dialami kyaipengasuh pondok pesantren dan berusia di atas 40 tahun yang tinggal di Yogyakarta.

\section{DASAR TEOR}

Jenis-jenis Mimpi. Benar adanya bahwa mimpi yang terjadi dalam diri seseorang dipengaruhi oleh kondisi tubuhnya dan kondisi psikologisnya. Namun, mimpi juga bisa berkaitan dengan spiritualitas seseorang. Menunut Subandi (1997) dan Nashori (1999), mimpi dapat digoiongkan menjadi tiga kategori, yaitu mimpi taraf fisik, mimpi taraf psikologis, dan mimpi taraf spiritual.
Mimpi taraf fisik yang dialami seseorang berkaitan dengan pengaruh kondisi fisiknya. Seseorang yang merasa Kelelahan seringkali menghadapi mimpi yang tidak mengenakkan. Mimpl taraf fisik ini juga berkaitan dengan pertumbuhan seseorang. Seorang pemuda yang baru saja menginjak masa agil baligh bermimpi berhubungan seks dengan seorang wanita sampai mencapai orgasme.

Mimpi taraf psikologis didapati sese. orang barkaitandengan suasana kejwaannya. Seseorang yang merasa bermasalah mendapatkan suatu mimpi d mana ia selalu cidatangi oleh orang yang sangat dibeneinya. Seorang anak yang baru saja bertengkar dengan orangtuanya bermimpi disiksa oleh ayah ibunya. Seorang siswa yang sangat ketakutan dengan perang dunia bermimpi seolah-olah perang itu benar-benar telah terjadi. Masih tergolong mimpi taraf psikologis adalah mimpi yang merupakan gema masa lalu. Di masa lalunya seseorang memiliki kawan yang selalu jadi musuhnya. Tanpa disadarinya perkelahian masa kecil hu sering hadir dalam tidurnya.

Mimpi taraf spirtuai diaiami seseorang akibat pengaruh alam gaib ke dalam kehidupan manusia. Mimpi tersebut bisa berasal dari Allah dan sebaliknya bisa datang dari setan. Mimpl yang berasai dari Allah sering dimaksudkan sebagai peringat anperingatan bagi langkah kehidupannya, sebagai pencerahan bagi kehidupan manusia, dan prediksi akan terjadinya sesuatu pada dirinya atau pada masyarakat. Sebagai contoh, seorang laki-laki seringkall bermimpi tentang bapaknya yang suciah meninggal dunia. Hal ítu merupakan peringatan baginya agar mendoakan orangtuanya.

Mimpi-yang berasal dari setan adalah mimpi yang dimaksudkan setan untuk menghasikan kegelisahan, keresahan, pesimisme, frustrasi dalam jwa manusia. Sebagai contoh, seseorang melihat kepalanya 
dipenggal dan orang-orang tertawa terpingkal-pingkal ketika sang kepala itu menggelinding. Apa yang dilihatnya dalam mimpi sangat menggelisahkan sehingga ia takut berbuat sesuatu.

Dalam penelitian ini mimpi yang ditelaah adalah gabungan mimpi psikologis dan mimpi spiritual, sehingga peneliti menyebut nya mimpi psiko-spiritual. Dalam mimpi jenis ini seseorang bermimpi dengan melibatkan kondisi psikologis dan pengaruh dari alam gaib.

Sumber-sumber Mimpi. Sebagian besar penakwil mimpi menjelaskan bahwa sumber mimpi ada tiga macam, yaitu kabar dari Allah, peringatan dari setan, dan mirmpi yang mencerminkan keadaan diri seseorang (fisik maupun psikologisnya) (Al-Killi, 1997).

Sumber pertama adalah Allah. Mirnpi yang berasal dari Allah adalah mimpi yang benar. la merupakan sejenis wahyu yang datang kepada orang yang baik dan dapat memberi kabar bak keadaan masa kini atau masa depan dan peringatan. Mimpi yang baik menjadikan seseorang merenungkan perbuatannya dan menjadi sadar akan kelalaiannya. Mimpi dapat juga merupakan teguran atas perbuatan jelek yang dilakukannya atau tindakan keliru yang diduganya baik, atau sebuah persahabatan baru yang dapat membawanya kepada kesengsaraan, atau sebuah penjelasan tentang peritakunya pada keluarga dan sahabatnya, atau bimt bingan spiritual, dan sebagainya. Rasulullah SAW bersabda: "Mimpi yang benar adalah salah satu dari empat puluh enam cabang kenabian."

Sumber kedua adalah setan. Mimpi yang berasal dari setan adalah mimpi yang salah. Mimpi ini berkonotasi dengan penipuan, kelicikan, kecemburuan, atau ketakutan, rasa sakit, bisikan rahasia yang tak patut didengar manusia, keterlibatan dalam percakapan duniawi, dan sebagainya Tentang mimpi yang berasal dari setan,
Rasulullah bersabda: "Seiring dengan semakin dekatnya hari akhir dunia ini, mimpi-mimpi manusia akan menjadi kacau." Pada suatu saat datang seseorang kepada Nabi Muhammad SAW dan menceritakan mimpinya. "Ya Rasulullahl Dalam mimpiku aku melihat kepalaku menggelinding of hadapanku, dan aku melihat diriku mencaricarinya." Nabi Muhammad meniawab: "Jangan bicara tentang tipuan setar".

Sumber ketiga adalah kondisi fisik dan psikologis manusia. Apa yang terjadi pada tubuh dan jiwa manusia memiliki pengaruh terhadap mimpi yang diperolehnya. Seseorang mungkin melihat dirinya duduk dengan orang yang dicintainya, orang yang takut sesuatu justru bermimipi apa yang ditakutkan itu, orang yang lapar bermimpi dirinya makan atau muntah, orang yang tidur d bawah terik matahari bermimpi melihat dirinya terbakar di neraka, saat sakit orang bermimpi dirinya menderita atau disiksa oleh orang lain, dan sebagainya.

Proses Terjadinya MImpl. Apa yang terjadi pada jiwa manusla saat ia tertidur? Pada saat tidur, jiwa (atau sebagian jiwa) manusia keluar dari tubuhnya. Jiwa itu bergerak ke langit Allah memegang iwa manusia yang fisknya sedang tidur itu. Dakam al-Qur'an Allah Azza wa jala berimtan:Aliahmemegang fiwa (orang) ketika ma tinyz dan (memegang) jiwa (orang) yang belum mat di waktu ticumya, maka Dia tahankan jiwa orang yang telah tetapkan kematiannya dan Dia lopaskan jiwa yang lain sampai batas waktu yang dientukan. (QS Az-Zumar, 39: 42).

Menurut Ali bir Abi Thalib karramallahu wajhahu (Nashori, September 1999), apa yang terkinat dalam mimpi sementara fiwa berada di sisi Allah di langit, maka ia adalah mimpi yang benar. Sedangkan apa yang terlihat dalam mimpi sementara jiwa telah dikembalikan ke wouh , maka ia adalah mimpi yang tidak benar. Sebagian ulama ahli mimpi mengatakan bahwa bukan jiwa 
yang hadir di sisl Allah df langit, melainkan pancaran jlwanya. Mereka berpendapat bahwa ketika seseorang tertidur, jiwanya memancar ke langit. Imam Ja'far Shadiq (1996) menandaskan bahwaseorang mukmin, jika la tidur keluarlah dari ruhnya suatu gerakan vertikal ke langit. Maka sesuatu yang dilihat ruhnya d alam malakut, di alam takdirdan tadbir (pengaturan) adalah hak (benar), dan segala sesuatu yang dilihatnya di burni hanyalah mimpl yang tak berarti. Dikatakan oleh Ja'far Shadiq, ruh yang keluar bukanlah keseluruhan ruh, karena kalau demikian seseorang akan meninggal dunia. Ja'far Shadiq berkata: "Tidakkah engkau melihat matahari pada tempatnya di langit, sementara cahaya dan sinarnya di bumi? Begitu juga ruh, ternpatnya df badan, dan gerakannya ke langir.

Senada dengan Ja'far Shadliq, Syaikh Abdul Ghani Nabulsi (dalam Al.Killi, 1997) mengungkapkan bahwa jika seseorang tertidur, jiwanya menjadi sernacam pancaran sinar yang melebar, atau seperti matahari, d mana la dapat melihat malaikat mimpi dapat menyingkapkan untuknya cahaya Tuhan yang terang benderang. Ketika cahaya Tuhan mengenai jwa seseorang yang tertidur, maka yang diperolehnya adalah mimpi yangbenar.

Dari penjelasan di atas dapat digambarkan bahwa saat tidur sebagian jwa ruh manusia bergerak secara ve tikal ke langit ke sisl Allah. Bila cahaya jwa manusia itu cemerlang, maka la akan disambut dengan cahaya Tuhan yang dlsingkapkan malaikat untuknya. Dalam keadaan seperti ini ia akan mendapatkan mimpi yang benar. Sementara bila cahaya ruh manusla itu redup atau suram, maka tidak akan bertemu cahaya Tuhan. Malakat tldak menyingkapkan cahaya Tuhan ltu sehlngga orang tersebut tidak mendapatkan mimpl yang benar. Dalam situasi seperti ini (situasi tanpa cahaya Tuhan) setan mencoba mem- pengaruhi manusia yang dirundung kecemasan, ketakutan, keputusasaan, dan mengambil jalan-jalan yang menyesatkan dirinya sendiri maupun orang lain.

Mlmpi yang dialami seseorang sangat berkaitan dengan kualtas Jasmani, kejwaan, dan spiritualnya saat maupun menjelarg tidur. Seseorang yang tubuh dan batinnya sehat dan nyaman akan sekurangkurangnya memiliki syarat untuk mendapatkan mimpl yang balk dan terh|ndar darl mimpl yang buruk. Sebaliknya, seseorang yang flsik dan psikologisnya banyak terkena beban, maka ia memiliki syarat untuk mendapatkan mimpi yang buruk.

Satu hal yang patut diperhat|kan adalah fislk dan psikls yang sehat dan nyaman akan menjadikan mlmpi seseorang dipengaruhl oleh Allah Azza wajalla. Sebaliknya, bila fisik dan psikis manusia kurang nyaman akan menjadikan setan memperoleh Kemudahan mempenganuhi mimpi manusia. Yang jelas, setan adalah makhluk yang selalu mencari upaya untuk mempengaruhi manusia,termasuk melalui mimpinya. Seseorang yang lelah jwanya akan dimungkinkan untuk dipengaruhi oleh setan-setan.

Mimpi yang Benar. Di antara mimpi yang dihadapi manusla, ada sebagian di antaranya yang tergolong sebagai mimpi yang benar. Mimpi yang benar adalah mimpi yang berasal dari Allah Azza wa jalla. Nashori (1999) mengungkapkan bahwa mimpl yang benar dapat berupa mimpi spiritual yang berisi peringatan, petunjuk, prediksi, dan retrospeksi.

Pertama, mimpi yang berisi peringatan bagi manusia untuk menghindari hal-hal yang buruk. Mimpi yang demikian bisa jadi memilikl materl dan alur cerita buruk (yang menyusahkan dan menyengsarakan bagi pemimpinya), tapl pada hakikatnya balk. Bisa jadi mimpi berisl siksaan, kecelakaan, kehancuran, pesimlsme. Namun, secara hakiki la sesungguhnya bermakna baik. 
Mimpi itu diciptakan Allah dan muncul dalam tidur manusia dengan maksud sebagai peringatan bagi manusia agar mengubah atau memperbaiki pikiran dan perilakunya. Sebuah contoh, seorang pemuda yang menghendaki seorang gadis menjadi istrinya bisa jad bermimpi yang isinya si gadis malah berakrab-akrab dengan pemuda lain. Hal ini adalah peringatan bahwa si gadis tidak cocok atau tidak patut hidup bersamanya. Contoh yang lain adalah mimpi yang dialami seorang pemuda yang sangat menyesal karena telah menghamili seorang gadis adalah mimpi yang memiliki dan alur centa buruk, namun sesungguhnya memiliki hakikat yang baik, yaitu agar ia lebih berhatihati dalam berkomunikasi dengan dan memperlakukan wanita yang didambakannya sebagai istri. Ada pelajaran bahwa kalau berzina maka ia akan menuai penderitaan hati yang luar biasa dan keinginan Untuk memisahkan diri dari lingkungan.

Dikatakan oleh ulama salaf yang memiliki otoritas dalam hal penalsiran mimpi, Ja'far Shadiq (1996), bahwa ada kalanya Allah dengan sengaja menghadirkan mimpi buruk dengan harapan seseorang menjauhkan perbuatan yang merugikan diri sendiri maupun orang lain.

"Seorang hamba, jika jika is bermaksiat dan Allah menginginkan kebaikan padanya, maka Allah memperlihatkan dalam mimpinya sesuatu yang dapat membuatnya ingin menjauh dari maksiat tersebut, dan sesungguhnya mimpi yang benar adalah salah satu dari tujuh puluh bagian kenabian."

Kedua, mimpi yang diperolehnya bisa jadi merupakan petunjuk atau jawaban atas permasalahan yang benar-benar dialaminya di alam nyata. Ibnu Sina adalah ilmuwan Islam yang sering kall menerima jawaban atas pertanyaan intelektualnya setelah beliau tidur. Dalam tidurnya Ibnu Sina mendapat ilham, sejenis dengan wahyu, yang berisi jawaban atas pertanyaan yang belum terjawab saat beliau terjaga. Dalam sebuah hadis Rasulullah SAW bersabda bahwa bermimpi yang benar merupakan salah satu ciri kenabian.

Ketiga, mimpi spiritual yang bersifat retrospektif. Mimpi jenis ini sebagian besar bertaraf psikologis dan fisik. Seseorang yang memimpikan teman-temannya d masa kecil atau di masa yang telah berlalu adalah satu contoh mimpi yang bersifat retrospektif. Namun, ada sebagian mimpi retrospektif yang tergolong spiritual, yaitu mimpi bertemu Nabi (Nabi Muhammad, dan nabinabi yang lain), mimpi bertemu dengan tokoh-tokoh spiritual yang dikenal sangat dekat dengan Allah (mimpi Al bin Abi Thalib, dan berbagai ulama' lain).

Keempat, mimpi yang bersifat prediktif. Mimpi yang terjadi dalam diri seseorang juga dapat menjadi prediksi masa depan pribadi, keluarga, dan bangsanya. Mimpl yang dialaminya menjadi kenyataan hidup beberapa saat kemudian. Mimpi itu seperti memberl gambaran tentang apa yang bakal terjadi pada seseorang ataU suatu bangsa tertentu. Mimpi demikian dapat digolongkan sebagai mimpi yang bermutu atau mimpi yang benar. Subandi (1997) menyebut mimpl yang demikian sebagai mimpi yang memiliki nilai prediktif. Nilai prediksi mimpi dibagi atas dua golongan, yaitu mimpi berskala personal dan mimpi yang berskala sosial.

Mimpi yang berskala personal menjangkau kehidupan pribadi dan keluarga si pemimpi. Sebagai misal, seseorang yang baru saja melakukan shalat istikharah mendapatkan mimpi tentang jodohnya di masa yang akan datang. Mimpi prediksi bisa remang-remang dalam pengertian hanya isyarat dan bisa juga dalam bentuk terang benderang. Mimpi prediktif yang bersifat personal juga terjadi pada zaman dahulu sebagaimana digambarkan dalam al-Qur'an. Di dalam kitab suci ini diceritakan bahwa ketika di dalam penjara, ada dua orang 
tahanan yang memiliki mímpi. Orang pertama bermimipi memeras anggur. Orang kedua bermimpi membawa rołi $d$ atas kepala yang sebagiannya dimakan burung. Mendengar kisah mimpi tersebut, Nabi Yusuf memprediksikan bahwa orang yang pertama akan bebas dan orang yang kedua akan disalib sampai meninggal dunia. Hal ini sesuai dengan ayat suci: Wahai kedua sahabatku sepenjaral Adapun salah seorang of antara kamu akan menuangkan anggur untuk minuman tuannya, sedangkan yang lan akan disalib dan burung-burung akan memakan darikepalanya. Demikianlah telah dijahthkan putusan mengenai perkara yang kalian tanyakanpadaku(OS Yusuf, 12: 41). Mimpi di atas adalah mimpi yang berskala individual.

Mimpi prediktif seseorang kadang berlaku bukan untuk dirinya melainkan untuk orang lain yang merupakan kerabat atau kawannya. Al-Killi (1997) mengungkapkan bisa saja istrinya, anaknya, rekan bisnisnya atau orang lain dengan nama yang sama. Hal ini terlihat dalam mimpi Abu Jahal ketika melihat dirinya menerima Islam dan mengucapkan sumpah dihadapan Rasulullah SAW. Pada kenyataannya, Abu Jahal mati sebagai orang kafir, dan anaknyalah yang mengalami apa yang dilihat Abu Jahaldalam mimpinya. Si anaklah yang menerima Islam dan bersyahadat di hadapan Rasulullah.

Mimpi prediktif yang berskaka sosial melibatkan kehidupan orang banyak. Mimpi itu menjadi semacam isyarat apa yang bakal terjadi di masa depan. Ketika Nabi Muhammad memimpin para sahabatnya ke Hudaybiyah, beliau melihat dalam sebuah mimpi bahwa beliau dan para sahabatnya memasuki kota suci Makkah (yang saat itu dikuasai orang kafir Quraisy). Dalam mimpi itu Nabi Muhammad melinat mereka mengelilingi Ka'bah dengan damai dan tenang. Allah Azza wa jalla membenarkan mimpi beliau.
Sesungguhnya Allah akan kepada Rasul-Nya tentang kebenaran mimpinya dengan sebenarnya, yaitu bahwa sesungguhnya kamu akan memasuki Masjidil Haram insya Allah dengan aman, dengan mencukur rambut kepala dan mengguntingnya pendek, sedang kamu tidak merasa ketakutan. Dia mengetahui qa yang tiada kamu ketahui. Dan selain itu diberi-Nya pula kemenangan of masa yangdekat(QS al-Fath, 48:27).

Dalam keadaan itulah Rasulullah dan kaum Muslim memasuki kota Makkah dan membersihkan rumah Allah (Ka'bah) dari kemusyrikan dan penyembahan berhala.

Mimpi yang berskala sosial juga dialami oleh Raja Ramses \# ketika Nabi Yusuf berada dalam penjara. Dalam mimpinya sang raja melihat tujuh ekor sapi betina yang gemuk-gemuk dimakan oleh tujuh ekor sapi betina yang kurus-kurus. Dalam mimpinya, raja juga melihat ada tujuh butir gandum hijau yang segar dan tujuh butir gandum lainnya yang kering kekuning-kuningan. Mencermati mimpinya yang agak lain dari biasanya, sang raja meminta nasehat kepada ilmuwan istana tentang mimpi itu. Para ilmuwan menyepelekan mimpi itu dan menganggapnya sebagai mimpi kosong belaka. Tetapi seorang tahanan yang telah bebas memberitahukan keberadaan dan kemampuan Yusuf dalam hal menafsirkan mimpi. Dengan ilmu yang dimilikinya Nabi Yusuf menyibak tabir mimpi itu dan berkata bahwa mimpi raja tersebut memiliki makna yang dalam. Bukan hanya menyangkut kehidupan pribadi sang raja, tetapi juga menyangkut kehidupan rakyat Mesir zaman itu. Nabi Yusut mengisyaratkan bahwa akan terdapat tujuh musim panen selama tujuh tahun yang akan disusul dengan tujuh tahun musim paceklik (QS Yusuf, 12:47-49). Ternyata mímpi Yusuf beriar.

Mimpi-mimpi Kyai. Apa yang dapat kita lakukan agar seseorang mendapatkan 
mimpi yang benar atau mimpi bermutu? Punyakah kyai mimpi-mimpi yang benar? Nashori (1999) mengungkapkan bahwa syarat atau modal yang umumnya dimiliki orang yang mendapat mimpi yang baik adalah kesalehan, empati terhadap kehidupan orang banyak, dan adanya kenyamanan fisik dan psikologis.

Modal pertama adalah kesalehan. Semakin taat seseorang kepada Aliah, semakin dimungkinkan baginya untuk mendapatkan mimpl yang benar. Hal ini sebagaimana dikatakan Rasulullah saat mendengar mimpi yang dialami oleh anak muda yang saleh, yaitu Abdullah Ibnu Umar. Ibnu Umar menuturkan bahwa ketika masih muda ia ingin sekali melihat sebuah mimpi yang benar dan mendengartakwil Rasulullah atas mimpl itu. Saat itu Rasuluilah sering bertanya pada orang-orang tentang mimpi mereka dan beliau segera mentakwilkannya. Abduilah berdoa: " $Y$ a, All'ah, jika Engkau menurunkan kebaikan bagiku, maka berikanlah kepadaku sebuah mimpi yang benar dan ditakwilkan Rasulullah untukku." Suatu malam Abdullah melihat sebuah mimpi di mana dua malaikat mengambil dirinya, dan membawanya kehadapan malaikat ketiga yang berkata kepada Abdullah. "Engkau orang yang saleh. Jangan hanya bicara!" Malaikat-malikat kemudian membawanya melihat api neraka yang dilipat seperti sebuah sumur. Di dalam melihat beberapa orang yang dikenainya tetapi malaikat mendorongnya ke sebelah Kanan menjauhi mereka. Ketika Abdullah terjaga, i menuturkan mimpinya kepada saudara perempuannya, Hafshah, istri Rasululiah. Hafshah kemudian menceritakan mimpinya kepada Rasulullah. Rasul berkomentar: "Sungguh, Abdullah adalah orang yang saleh. Akan baik jika ia meningkatkan lbadah shalat malamnya." Setelah itu Abdullah semakin teratur menjalankan shalatnya.
Berdasarkan penjelasan di atas dapat diketahui bahwa seseorang yang saleh, yang memiliki kedekatan dengan Allah, dimungkinkan memiliki atau mengalami mimpi yang benar. Oleh karena itu, seorang kyai yang umumnya memiliki kedekatan dengan Ällah juga dimungkinkan memiliki atau mengalami mimpi-mimpi yang benar. Jenis-jenis mimpi spiritual yang bersifat prediktif, retropsektif, peturjuk dan peringatan akan pilihan hidup adaiah tema-tema mimpi yang akrab dengan kehidupan mereka.

Modal yang kedua adalah empati kepada kehidupan orang banyak dan komitmen untuk menolong orang lain. Kalau seseorang selalu memikirkan kebaikan dan kebahagiaan banyak orang. maka Allah berkenan untuk menghadirkan pengetahuan yang tibatiba dan benar, bahkan yang bersifat prediktif, melaiul mimpi. Apa yang diaiami Ramses ll pada zaman Nabi Yusuf adalah mimpi yang dialami seorang raja yang sangat memperhatikan nasib rakyatnya dan keinginan untuk menghadirkan kebaikan bagl kehidupan mereka. Allah berkenan mengirimkan cahaya pengetahuan melalui mimpi kepada raja tersebut yang ditafsirkan oleh Yusuf. Mimpi yang benar itu akhirnya menghindarkan bangsa Me sir dari ancaman terkena musim paceklik berkepanjanyan,

Umumnya kyal tinggal di lingkungan yang menyatu dengan masyarakatnya, bahkan sebagian besar Pondok Pesanten yang mereka asuh berada di tengah-tengah masyarakat desa. Semangat yang mereka miliki adalah komitmen untuk memperbaharul atau memperbaikl masyarakat. Dengan komitmen yang tinggi disertai oleh kehadiran yang riil dalam kehidupan masyarakat, mereka memiliki empati atas kehidupan masyarakatnya. Dengan empati yang tinggi itulah sang kyai selanjutnya memilliki kesempatan yang luas untuk mendapatkan mimpi-mimpi yang benar, bahkan yang bersifat prediktif dan berdimensi sosial. 
Modal yang ketiga adalah menyamakan kondisi fisik, psikologis, spiritual menjelang tidur. Fisik dibebaskan dari rasa sakit dan kelelahan. Psikologis dibebaskan dari stres, kecemasan, dan sebagainya. Lebih dari itu adalah spiritualitas seseorang dinyamankan pula. Secara spiritual orang yang hendak tidur berwudhu dan selanjutnya memohon perlindungan kepada Allah dari kemungkinan terkena godaan setan. Dikatakan oleh Ja'far Shadiq (1996): "Jika seseorang ingin mimpl yang benar(shadiqah), maka hendaklah ia tidur dengan wudhu, miring ke kanan, dan berdzikir kepada Allah."

Seorang kyal yang banyak melakukan dzikir dimungkinkan memiliki kondisi psikologis yang relatif stabil. Dzikir kepada Allah sendiri memiliki efek menenangkan, sebagaimana diungkapkan oleh penelitian Effa Naila Hady (Bastaman, 1996) maupun penelitian Ratna Djuwita (Bastaman (1996). Dengan kondisi psikologis yang tenang dan stabil, sang kyai lebih siap untuk menerima mimpi yang benar.

Kesempatan kyai untuk mendapatkan mimpi yang benar menjadil terbuka, terutama karena mereka telah melewati fase futuh. suatu fase d mana seseorang memiliki kemampuan untuk memiliki pengalaman dan pengetahuan yang meyakinkan tentang hakkkat kehidupan dan kenyataan-kenyataan hidup yang bersifat metaempiris (Nashori, 2000).

\section{METODE}

Subjek penelitian ini adalah tokoh agama atau kyai of Yogyakarta. Secara khusus, mereka adalah pimpinan atau pengasuh pondok pesantren dan telah berusia 40 tahun. Pemilihan usia d atas 40 tahun ini didasarkan pada pertimbangan bahwa pada usla ini manusia telah memasuki fase futuh. Pada fase inl telah dimungkinkan munculnya kemampuan-kemampuan spiri- tual dan bahkan juga kemampuan supranatural. Jumlah responden adalah lima orang kyai.

Teknik pengumpulan informan adalah purposive. Teknik inidipakai dengan menggunakan kriteria sebagaimana yang telah dituliskan. Sebagai pelengkap digunakan snow ball sampling (teknik sampling bola salju), yaitu menggunakan informasi dari seorang subjek yang mengenal subjek lain yang memiliki kemampuan atau pengalaman yang mirip dalam masalah mimpi .

Dalam penelitian ini data yang berisitematema mimpi pskko-spiritual kyai diungkap derigan menggunakan wawancara mendalam. Pertanyaan penelitian diarahkan untuk mengungkap tema-tema mimpi psiko-spiritual, yaitu prediksi, retrospeksi, petunjuk, dan peringatan. Pertanyaan-pertanyaan utama yang hendak diajukan adalah:

1. Apakah Kyai memiliki pengalaman bermimpl yang bernuansa prediktif? Apa saja mimpinya?

2. Apakah Kyai memiliki pengalaman mimpi yang bernuansa retrospektif? Adakah bermimpi bertemu dengan Nabi-nabi?

3 Apakah Kyai memiliki pengalaman mimpi yang berisi petunjuk?

4. Apakah Kyai memiliki pengalaman mimpi yang berisi peringatan?

5. Apa proses yang dilakukan sehingga muncul mimpi yang benar?

6. Dalam konteks sosial apa mimpi-mimpi its bermunculan?

Setelah dilakukan wawancara deskriptif, selanjutnya dilakukan analisis isi. Analisis isi digunakan untuk memahami apa yang dkatakan ifforman berkaitan dengan masalah mimpi. Secara teknis, setelah wawancara yang dilakukan dengan perekam, kegiatan riset dilanjutkan dengan penulisan verbatim. Setelah semua naskah dibaca, peneliti mengelompokkan isl mimpi ke dalam empat tema. 


\section{HASIL PENELITIAN}

Setelah dilakukan wawancara dengan lima subjek diketahui bahwa subjek telah mengalami mimpi yang bertaraf psiko-spiritual, di samping mimpi yang bertaraf fisik dan psikologis. Sebagian mimpi psiko-spiritual bersifat prediktif, baikyang ada kaitanrya dengan diri prlbadi (personal) maupun dengan banyak orang (sosial). Sebagian mimpi berisl pengetahuan tentang kehidupan masa lalu (retrospeksl), peringatan, dan petunjuk. Selengkapnya inilah tema-tema mimpi yang muncul dalam tidur kyal pimpinan Pondok Pesantren di Yogyakarta.

\section{Tema-tema Mimpi Retrospektif}

Isi mimpi yang pertama adalah mimpi retrospektif bertemu nabi, terutama Nabi Muhammad SAW. Berdasarkan keyakinan Islam, mimpi bertemu Nabi Muhammad adalah mimpi yang benar, dalam pengertian bahwa alam ruhani subjek benar-benar bertemudenganalam nuhari Nabi Muharnmad. Berikut ini adalah mimpi bertemu Nabi yang berslfat sosial. Disebut berskala sosial dikarenakan d dalamnya tersurat pesan agar isi subjek meneruskan apa yang dilakukan Rasulullah, yaitu berdakwah dalam rangka menyebarkan amar ma'uf dan nahi munkar.

Saya mimpi pertama kall ketemu Nabi (Muhammad), Saya rasanya df Pondok Tempuran Magelang. Di sana ada masfid tua. Kelihatannya ada pengajian akbar. Semua kendaraan berhenti. Tidak ada hadirin yang tidak menghadap ke arah panggung. Mikrofomya banyak sekall. Yang mau ceramah Nabi. Bellau datang disertai malalkat Jibril, Abu bakar, Umar, dan Ail. Utsman bin Affan tidak ada. Tidak ada Ulsman bin Affan di sana, karena kalau mimoi Utsman katanya tanda baki dapat musibah.

Yang mengherankan, yang datang Nabi, kok nggak ada yang mencoba salaman dengan Nabi. Saya naik panggung mem- beranikan diri salaman. Setelah itu saya dikenalkan oleh Nabi kepada Jibril, Abu Bakar, Umar, dan Ali. Terus, saya dipersilakan. Sampeyan saja yang ceramah, begitu kata Nabi. Terus, Nabi ke kamar saya of Pondok. (KHAMM)

Berbeda dengan mimpi di atas, mimpi yang berikut InI tergolong dalam Isi mimpi mimpi yang berskala personal.

Saya meilhat barisan Nabi-nabi. Saya mau menemui mereka. Say a cegat di falan, bahkan say a melewati jalan pint as Na mun, saya hanya dapat meilhat mereka dari kejauhan. (KH AMM)

isi mimpi yang kedua adalah mimpi retrospektif bertemu Nabl Khidzir. Nabi Khidzir dalam Islam adalah Nabi yang berhubungan dengan masalah air. Mimpi bertemu Nabi Khidzir ini dapat dikelompokkan dalam mimpi berskala personal.

Say a datang ke kamar seseorang yang sudiah tua. Kami bersalaman. Saya pegang tangannya, temyata tidak ada tulangnya. Dla lari, kemudian saya kejar. Dia masuk ke air, sampai masuk ke terowongan dalam air itu. Saya tanya siapa dia Jawabnya ternyata Nabi Khidzir. (KH AMM)

\section{Tema-tema Mimpi Prediktif}

Isi mimpi yang ketiga adalah mimpi prediktif akan jadi seseorang yang limunya ditimba orang lain tanpa henti. Mimpi ini adalah mimpi kawan dekat subjek penelitian tentang subjek. Dikarenakan menyangkut kehidupan orang banyak, m/mpi ini dapat dikelompokkan sebagal mimpi berskala sosial.

Ini bukan mimpi saya sendiri, tetapi mimpi orang lain tentang saya. Seseorang bermimpi saya membuat sumur. Sumuryang saya buat itu ter nyata banyak aimya. Orangorang berbondong-berbondong dan silih berganti mengambi airitu. Air itu seakan tidak akan habis. Terus diambil dan tidak habis.

Teman saya itu menafsirkan bahwa saya akan mengasuh Pondok Pesantren. 
Orang-orang berbondong-bondong menimba ilmu di tempat saya men gas in santri-santri itu. Mimpi itu benar. Saat ilu saya tidak punya asumsi akan mengasuh PP tersebut, karena orang lain yang lebih muda dari saya sudah memegangnya. Ternyala saya dipercayai pimpinan sebuah perguruan tinggi Untuk mengasuh Pondok Pesantren Perguruan Tingggi. (KH TM)

Isi tema yang keempat adalah mimpi prediktif tentang jumlah kursi yang akan diperoleh oleh partal tertentu. Ini adalah salah satu jenls mimpi prediktif, sebuah mimpi yang memberikan gambaran tentang apa yang bakal terjadi d masa datang. Mimpi ini dapat digolongkan sebagal mimpi berskala sosial dikarenakan menyangkut kehidupan banyak orang.

Waktu ilu .... (sebuah partai) di Bantul membuat perkiraan berapa kursi yang bakal diperoleh. Berdasarkan mimpi, saya memperoleh pelunjuk bahwa jumlah kursi partai tersebut adalah $8-9$ buah. Temanteman memprediksi 15 buah. Saya tetap yakin 8 Hasil benarnya, 8 buah. (KH AMM)

Isi mimpi yang kelima adalah mimpi akan terjadinya letusan gunung Merapi. Ini juga salah satu jenis mimpi yang memberikan tanda bakal terjadinya sesuatu, dalam hal ini adalah letusan Gunung Merapi, di masa yang akan datang. Mimpi ini dapat dkelompokkan sebagal mimpi berskala sosial karena dampak letusan Merapi menyangkut kehidupan banyak orang.

Salah salunya saya memang bermimpi meilhat gunung merapi meiotus. Ternyata benar. Mimpi itu memberi alamat alau tanda kepada saya. (KH AMU)

Is! mimpi yang keenam adalah mimpl prediktif akan melaksanakan ibadah haji d tanah sucl Makkah, tepatnya d Masjidil Haram. Mimpi ini termasuk mimpi personal.

Sebelum haji saya bemimpi berada $d$ tanah suci, berada of Makkah atMukarramah. Saya bermimpi di mana situasinya adalah keadaan orang-orang di dalan masjid. Saya termasuk ada di dalamnya Beberapa tahun kemudian saya naik haji dan mengalami persis sama sebagaimana yang saya ihat of dalam mimpi. (KH TM)

3. Tema-tema Mimpi yang Bersifat Petunjuk Isi mimpi yang ketujuh adalah mimpi yang berisi petunjuk tentang hal yang sebaiknya dilakukan dalam upaya menghadirkan hal yang manfaat bagi banyak orang. Kadang petunjuk itu berupa suatu gagasan yang memiliki unsur kebaruan atau kreativitas. Hal inl sebagaimana mimpl seorang kyal yang mendapat petunjuk dari Allah untuk membangun Pos Kesehatan Pesantren. Mimpl ini dapat dlgolongkan sebagai mimpl berskala sosial.

Saya harus mengembangkan Pondok Pesantren saya. Tapi, bagaimana? Saya akhimya melakukan shalat istikharah. Saya mendapat mimpi untuk membangun pas Kesehatan Pesantren. Ini belum ada $d$ pesantren-pesantren yang lain. Marganya juga murah. Ternyała Poskestren ini maju pesat. Dua obtter di sini mendapat prestasi bagus, mereka mendapat hadiah hall gratis. (KHAMM)

Isi mimpi yang kedelapan adalah mimpi yang berisi petunjuk tentang obat yang dapat digunakan untuk menyembuhkan penyakit. Sebagal ulama atau kyal dikenal memiliki pengetahuan dan doa yang menyembuhkan. Untuk mendapatkan pengetahuan tentang kondisl kesehatan dan obat apa yang sebaiknya diberikan sang kyal banyak melakukan dzikir. Ide seringkali datang melalui saat tidur, di samping kadang tlbatiba pengetahuan itu sudah ada dalam hati. Mimpi ini dapat dikategorikan sebagai mlmpi berskala sosial.

Saat itu ada seorang anak berusia tiga tahun yang selama seminggu suhu badannya of atas normat. Saya berdzikir secukupnya. Saat tidur saya bermimpi. 
Akhimya saya suruh si bapkk dai anak yang sakit untuk menyembellh ayam. Darah segamya harap dilaburkan ke selisuh fubuh anak. Ternyata sembuh. (KH YM)

Saya menyarankan kepada seorang bu yang terkena diabetes miletus agar minum kuah sayur kacang. Sayangnya, dia ngeysi, tidak mau mencoba. Akhirnya, Allah tidak membuatnya segera sembuh. (KH YM)

isi mimpi yang kesembilan adalah mimpi yang berisi petunjuk agar seseorang menjalani kehidupan secara tabah. Mimpi ini tergolong mimpi berskaia personal.

Saya pernah bermimpi Nabi lbrahim. Saya melihat bagaimana Nabi ibrahim menjatuhkan berhala-berhala yang disembah oleh raja den bangsanya saat itu. Sang raja marah besar dan menanyai lbrahim yang melakukannya. Ibrahim menjawab: "Tanyakan saja kepada berhala terbesar yang di lehernya ada kapak besar. Bukankah dia Tuhanmu?" Saya juga menyaksikan klabahan lbrahim saat bellau dibakar-bakar hidup-hidup oleh raja dan prajurithya.

Mimpi Nabi lbrahim itu seakan membawa pesan pribadl bagi saya. Saat itu saya membutuhk an dukungan moral untuk menyelesaikan tugastugas saya. Motalu! mimpi itu ada pesan, kalau memperjuangkan sesuatu semestinya orang bekerja keras, beker ja luar blasa, dan mudah putus asa. ibrahmim menjadi contoh bagi saya agar selalu berusaha dengan penuh ketabahan. (KHTM)

4. Tema-temaMimpiyangBersifatPeringatan

Isi mimpi yang kesepuluh adaiah mimpi peringatan yeng berisi tentang calonjodoh atau calon pasangan hidup yang sebaiknya dihindari. Daiam Islam dlkenai shalat istikharah, shalat yang di dalamnya ada kesempatan bagi yang melakukannya untuk mendapatkan petunjuk atas pilihan hidup yang beium dapat diputuskannya. Salah satunya adalah masalah jodoh. Melalui mimpi bisa jadl seseorang diperingatkan oieh Tuhan untuktidak meneruskan pilihan terhadap orang yang sejauh ini telah didambakannya. Mimpi peringatan inl dapat dikelompokkan sebagai mimpi berskala personal.

Ya saat itu saya didorong orangtua untuk menikah. Dalam suatu mimpi saya tercenung dengan keluarga gadis itu akan diangkat, dlambil mati deh-Nya ...

Setelah shalat istikharah ketiga kalinya, saya diajak ibu saya ke Bringharjountuk membeli emas. Saya kaget karena bu saya membelikan saya emas 18 karat. Dalam benak aaya mengapa ibu membelikan saya emas 18 karat, padahal emas yang baik adalah yang 24 karat.

Setelah bangun saya matur kepada ayah saya. Beliau bilang, "Jangan diteruskan niat nikah dengan anak tersebut. " (KH AMU)

Sewaktu saya masih muda dulu saya mengharap seorang wanita menjadl istrl saya. Saya melakukan shalat islikharah beberapa kall. Dalam mimpi itu ternyata da malah bersama orang lain. Dia duduk di antara bambu-bambu dan bercumbu dengan orang lain. Penafisiran saya waktu itu, dia saya har spkan mendampingi saya, temyata malah bersama orang lain. Akhimya saya mengubah haluan. Saya cari orang lain. ( $\mathrm{KH}$ TM)

Isi mlmpi yang kesebelas adalah mimpi yeng berlsi peringatan untuk menghindari tanda tertentu. Mimpi yang dialami seseorang bisa merupakan peringatan untuk tidak melakukan atau mengakhiri suatu tindakan atau pilihan. Isi m/mpi bisa berupa tandatanda atau peristiwa-peristwa. Salah satunya adalah berupa tanda warna. Mimpi ini berskala personal.

Memang ada implan-impian yang mengandung alamat. Bapak saya, kalau istikharah, blasanya tidur. Kalau mimpi kok ada benda hijau atau puth, itu artinya bagus. 
Kalau mimpi kok ada benda merah itu kurang baik. Umpanya mempunyai cita-cita, distikharahi, dan kemudian tidur, dan yang terlihat warna merah, liu artinya jangan diteruskan. (KH AMU)

\section{Proses Menuju Mimpi yang Benar}

Untuk mendapatkan mimpi-mimpi spiritual sebagaimana diungkapkan, ada sejumlah usaha yang dilakukan kyai. Usaha yang terutama adalah pendekatan diri kepada Tuhan Yang Maha Esa.

Saya berproses, ya pakai puasa, pakai wirid-wirid tertentu. Baru setelah ilu ketemu Nabi. (KH AMM)

Kalau ingin bermimpi bertemu Nabi (Muhammad) ya membaca shalawat. $(\mathrm{KH}$ AMU)

\section{PEMBAHASAN}

Darl paparan of atas dapat diketahui bahwa tema-tema mimpi yang berlangsung pada kyai meliputi mimpi psiko-spiritual yang berisi retropeksi (bertemu Nabi Muhammad, bertemu Nabi Khidzir), prediksi (sumuryang tak habis airnya walau ditimba terus menerus, kursi yang diperoleh partai, Merapi akan meletus), petunjuk (pendirian pos kesehatan pondok pesantren, obat untuk menyembuh-kan penyakit, meniru Ibrahim yang tabah menjalani kesulitan hidup), peringatan (jauhi seseorang yang diinginkan sebagai cal on jodoh, hindari warna merah).

\section{Dinamika Psikologis}

Kyai dikenali sebagai pribadi yang memilikl kesalehan yang tinggi. Dengan kedekatannya kepada Aliah Azza wa jalla yang dilakukan dengan dzikir, pembacaan shalawat, puasa secara intensif, kyai cukup disiplin dalam melakukan proses pembersihan diri. Dalam kondisi psiko-spirtual bersih, sang kyai telah memiliki kesiapan untuk mendapatkan mimpi yang benar yang berasal dari Allah Azza wa jalla. Dalam kondisi demikian sang Kyai slap memperoieh gambaran yang benar tentang kenyataan masa depan (prediksi), gambaran masa lalu (prospeksi), hal-hal yang semestinya dilakukan (petunjuk), dan halhal yang semestinya dihindarl atau dihindarkan (peringatan). Dengan demikian, dapat disimpulkan bahwa kesalehan menjadi modai atau syarat untuk mendapatkan mimpi yang bernuansa psiko-spiritual.

Mimpi psiko-spiritual yang kaya sebagaimana digambarkan dalam penelitjan juga berkaitan dengan adanya keterlibatan sang kyai dengan kehidupan sosial bersama masyarakat yang ada di sekitamya. Individu yang menyediakan ruang psiko-spiritualnya untuk memberi perhatian kepada masyarakat akan memiliki empati dan juga kasih sayang kepada masyarakat. Dalam keadaan demikian mereka selaiu berusaha agar ada sesuatu yang berharga yang dapat mereka berikan kepada masyarakat. Komitmen untuk berbuat sesuatu yang berharga bagi masyarakat ini, ditunjang oleh kedekatan kepada Tuhan, menjadikan mereka memiliki ruang psiko-spiritual yang luas. Dengan ruang psiko-spiritual yang demikian ini mudah memperoleh ide atau petunjuk tentang hal yang terbaik dari Allah Sang Pencipta.

Dengan ruang psiko-spiritual yang kaya dengan berbagai macam pengalaman ruhani, kyai-kyai di Yogya ternyata bermimpi sesuatu yang tergolong orisinal, sulatu mimpi yang arahnya adalah upaya perbuatan baik bagi masyarakat. isi mimpinya di antaranya adaiah petunjuk periunya dlbangun Pos Kesehatan Pondok Pesantren. obatyang paling digunakan untuk menyembuhkan penyakit, dan sebagainya. Kehidupan kyai di tengah masyarakat ternyata disertai dengan keterlibatan yang nyata dengan masyarakat, sehingga keterlibatan iru juga hadir dalam bentuk rnimpi. 


\section{Keterlibatan Kyai dalam Kehidupan Sosial}

Keterlibatan lain kyai dalam kehidupan masyarakat juga terlihat dari kesediaan kyai untuk mendengarkan, menakwilkan atau menafsirkan, dan meminta masyarakat untuk menganggap mimpi sebagai bunga tidur. Respon-respon yang diberikan kyai diupayakan sesuai dengan konteks kondisi fisik dan psikologis seseorang. Keterlibatan semacam ini memberikan gambaran bahwa ada keterkaitan yang erat antara kyai dengan masyarakał yang ada di sekitarnya.

Dari mimpi-mimpi yang diperoleh dapat diketahui bahwa mimpi spiritual yang dialami sebagian di antaranya adalah mimpi-mimpi yang bertaraf sosial, artinya menyangkut kehidupan orang iain atau orang banyak. Reberapa d antaranya adalah mimpi pendirian pos kesehatan pondok pesantren, jumlah kursi yang diperoleh partai tertentu dan obat yang akan digunakan orang-orang yang sakit.

Keterlibatan dalam aktivitas sosial ini ternyata memiliki ujung pada lahimya mimpi yang bersifat sosial. Mimpi yang demikian tidak selalu terjadi pada orang-orang yang dekat dengan Allah Azza wa jalla Berdasarkan catatan sejarah diketahui bahwa Raja Ramses pada jaman Nabi Yusuf bukan lah seorang raji yang Muslim (yang berserah diri kepada Allah. Namun, yang pasti ia adalah raja yang peduii terhadap nasib bangsanya. Dengan empati, cinta, kasih sayang terhada bangsanya, Allah berkenan mengirimkan mimpi itu kepada Sang Raja.

\section{Mimpi dan Syariat Islam}

Salah satu permasalahan yang berkaitan dengan mirnpi dari Kyai adalah kemungkinan seseorang menjadikan mimpinya sebagai dasar untuk mengambil keputusan hukum. Perlu disampaikan bahwa apabila ada perbedaan pesan mimpi, sekalipun mimpi tu berasal orang yang sangat dekat dengan Allah, dengan dalil-dalil yang ada dalam kitab suci, maka yang patut diikuti adalah apa yang diterangkan dan ditetapkan oleh Allah dalam kitab suci.

Dalam kehidupan masyarakat bisa jadi ditemukan sebagian orang yang mempercayai orang tertentu, termasuk kyai, memiliki mimpi yang benar dan mereka menganggap bahwa mimpi kyai itu dapat dijadikan keputusan untuk melakukan atau tidak melakukan sesuatu sambil meminggirkan peran dalif-dalil Tuhan yang ada dalam kitab suci. Hal seperti ini jelas tidak dapat diterima oleh nilai Islam.

\section{SIMPULAN DAN SARAN}

Dari penjelasan of atas dapat disimpulkan bahwa tema-tema mimpi spiritual kyai meliputi pengetahuan bersifat prediktif, baik yang ada kaitannya dengan diri pribadi (personal) maupun dengan banyak orang (sosial). Sebagian mimpi berisi pengetahuan tentang kehidupan masa lalu (retrospeksi), peringatan, dan petunjuk.

Adanya mimpi psiko-spiritual tersebut berkaitan dengan kedekatan kyai dengan Allah Azza wa jalla dan keterlibatan kyai dengan persoalan-persoalan hidup masya rakat.

Saran untuk penelitian berikutnya adalah nendaknya: (1) peneliti menggunakan subjek kyai dalam jumlah yang lebih besar, (2) pertu juga meneliti mimpi dari seseorang yang dekat dengan Allah dari kalangan wanita, (3) sangat baik bila dilakukan penelitian dengan memperhatikan perubahan mimpi dari waktu ke saktu dari diri subjek, (4) patut dilakukan penelitian untuk mengetahui tema mimpi antara kyai dengan tokoh-tokoh dari agama lain, seperti pastor, pendeta, bikhu, rabbi, dan seterusnya, (5) juga perlu dilakukan perbandingan tema mimpi antara orangorang dari profesi yang berbeda. 


\section{DAFT AR PUSTAKA}

Al-Killi, M. M. 1997. Ensikiopedi Takwif Mimpi slam Ibou Siriz Bandung: Pustaka Hidayah.

Amstrong, A 1996. Kunci Memasuki Dunia Tasawut. Bandung: Penerbit Mizan.

Bastaman, H.D. 1996. Integrasi Psikologi dengan Islam: Menuju Psikologi Isiami. Cetakan Kedua. Yogyakarta: Yayasan Insan Kamil dan Pustaka Pelajar.

Berry, J. W. Poortinga, Y. H., Segall, M.

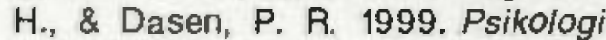
Lintas Budaya: Riset dan Aplikasi. Jakarta: PT Gramedia Pustaka Utama.

Chaplin, J.P. 1997. Kamus Lengkap Psikologi. Cetakan Koempat. Jakarta: Rajawali Press.

Hall, C.S. dan Lindzey, G. 1998. Teori Kepribadian. Yogyakarta: Penerbit Kanisius.

Jawa Pos. 2000. Wawancara Dengan Hidayat Nur.Wakhid.Jawa Pos, Oktober 2000 .

Khaldun, I. 2000. Muqaddimah. Cetakan Keempat. Jakarta: Pustaka Firdaus.

Madjid, N. 1997. Bilik-bilik Pesantren: Sebuah Potret Perjalanan. Jakarta: Penerit Paramadina.

Moleong, L. J. 1980. Metodologi Penelitian Kualitatif. Bandung: Penerbit Rosdakarya Remaja.
Mubarok, A 2000. Jiwa dalam al-Quran. Jakarta: Penerbit Paramadina.

Nashori, F. 1999. Optimasi Kreativitas Melalui Religiusitas. Majaiah Logis, No. 1, September 1999.

Nashori, F. 1999. Aplikasi Psikologi Islami. Diktat Kuliah (tidak ditemitkan). Yogyakarta: Fakultas Psikologi UII.

Nashori, F. 2000. Perspektif Psikologi Islami tentang Perkembangan Manusia. Makalah disampaikan dalam Simposium Nasional Psikologi Isiami IV, diselenggarakan Fosimamupsi Pusat, Fakultas Psikologi UI, Depok, 17-20 Juli 2000 .

Shadiq, I. J. 1996. Mengungkap Rahasia Mimpi. Jakarta: Penerbit Lentera.

Subandi. 1997. Relevansi Mimpi. Majalah Shutiyah, No. 1, 1997.

Partadireja, A. 1997. Al-Qur'an, Mujizat, Karomat, Maunat, dan Hukum Evolusi Spiritual. Yogya: PT Dana Bhakti Prima Yasa.

Thou less, R. H. 1995. PengantarPsikologi Agama, Jakarta: PT Raja Grafindo Persada.

Oardhawy, Y. 1998. Wangsit, Kasyaf, Mimpi, Jimat, Perdukunan dan Pengobatan Spiritual: Tinjauan Islam. Jakarta: Robbani Press.

Yayasan Insan Kamil. 2000. Perspektif Psikologi Islami tentang Kepribadian. Mimpi, Kreativitas, Agresivitas. Hasil Diskusi Psikologi Is/ami Yayasan Insan Kamil 1998-2000. Yogyakarta: yayasan Insan Kamil. 